\title{
AUDITORY-VISUAL AND VISUAL-VISUAL EQUIVALENCE RELATIONS IN CHILDREN
}

\author{
PAUL M. SMEETS \\ Leiden University \\ DERMOT BARNES-HOLMES \\ National University of Ireland at Maynooth
}

Previous research has suggested that persons with mental retardation evidence equivalence more readily after being trained on auditory-visual than on visual-visual match-to-sample tasks. The present study sought to determine if this discrepancy is also apparent in normally capable preschoolers and whether the derived class-consistent test performances could have resulted from applying the same verbal label to all stimuli of a class or from intraverbal naming. Sixteen 5 -year-old children received training on auditory-visual and visual-visual match-to-sample tasks. Then they were tested for equivalence, requested to name each stimulus, and given the opportunity to sort the stimuli according to equivalence-class membership. Unsolicited naming responses were recorded during all arbitrary matching tasks. All 16 children passed the auditory-visual equivalence test, 12 of whom also passed the sorting test. Only 9 of these children passed the visualvisual equivalence test, 5 of whom also passed the sorting test. The performances during the equivalence and sorting tests appeared not to be related to the names given during the presentation or after the presentation of the matching tasks.

Studies on stimulus equivalence typically start with the training of multiple match-to-sample tasks with visual stimuli as samples (e.g., A-B, $A-C)$. As a result thereof, most verbally capable humans display novel stimulus relations that are consistent with symmetry (B-A, C-A) and equivalence (B-C, C-B) (Sidman, 1994, 2000). Among the variables that have been reported to affect equivalence formation is stimulus naming. Studies have shown that equivalence formation can be facilitated by (a) training participants to label designated same-class stimuli with a common name or to intraverbally name the correct sample-comparison pairs (Dugdale \& Lowe, 1990; Eikeseth \& Smith, 1992; Goyos, 2000; Lowe, Horne, Harris, \& Randle, 2002; Saunders, Saunders, Williams, \& Spradlin, 1993; Wulfert, Dougher, \& Greenway, 1991), (b) using stimuli with names

Correspondence should be sent to Paul M. Smeets (Smeets@fsw.leidenuniv.nl), Department of Psychology, Leiden University, P.O. Box 9555, 2300 RB Leiden, The Netherlands. 
that rhyme along class membership (Randell \& Remington, 1999), and (c) using easy rather than difficult to name stimuli (Holth \& Arntzen, 1998; Mandell \& Sheen, 1994). These findings, together with the fact that humans with limited naming abilities frequently do not show equivalence (Barnes, McCullagh, \& Keenan, 1990; Devany, Hayes, \& Nelson, 1986; Eikeseth \& Smith, 1992; Goyos, 2000; but Carr, Wilkinson, Blackman, \& Mcllvane, 2000), have been taken as evidence in support for the position that naming is the sole means of establishing arbitrary stimulus classes (Horne \& Lowe, 1996; Lowe et al., 2002). In the words of Horne and Lowe (1996, p. 227), "Naming is stimulus-classifying behavior." From this perspective, also referred to as the "naming account," it should come as no surprise (Horne \& Lowe, 1996) that match-to-sample tasks with dictated names as samples should be easier to learn and should more readily produce equivalence relations than match-to-sample tasks with visual stimuli as samples (Green, 1990; Sidman, Willson-Morris, \& Kirk, 1986). On balance, however, in both these studies no relation between equivalence and class-consistent naming could be established.

In the study by Sidman et al. (1986), 2 normally capable 5 -year-old children and 4 institutionalized adults with mental retardation were trained on two sets of match-to-sample tasks, one with dictated names as samples ("A"-B, "A"-C) and one with visual stimuli as samples (D-E, D-F). Then the participants received the opportunity to demonstrate equivalence (B-C, C-B; E-F, F-E) and symmetry (E-D, F-D), and to name the visual stimuli of each set (oral naming test). Both children readily demonstrated auditory-visual and visual-visual equivalence. The adults with mental retardation also showed auditory-visual equivalence but most of them no visual-visual equivalence unless symmetry had been repeatedly tested or trained. Only some participants labeled same-class stimuli of the auditory-visual set with a common name (e.g., B1-"A1," B2"A2"), one of whom also used a common name with the stimuli of the visual-visual set. In all other instances, the participants labeled the stimuli inconsistently or did not name at all. Similar findings were reported by Green (1990). In that study, adults with mild and borderline mental retardation (IQ 73-79) participated. Two participants were first trained on auditory-visual tasks ("A"-B, "A"-C). Then they received a series of tests, one assessing equivalence (B-C, $C-B)$, one assessing class-consistent naming (B-"A," $C$-" $A$ "), and one in which they were given the opportunity to sort the $B$ and $C$ stimuli into two piles, one of class-1 stimuli and one of class-2 stimuli. Subsequently, they were trained on match-to-sample tasks with all visual stimuli (D-E, D-F), followed by equivalence (E-F, F$E)$, symmetry $(E-D, F-D)$, naming, and sorting tests. The other three participants received the same program but in the reversed order (visualvisual before auditory-visual). Although all participants eventually evidenced auditory-visual and visual-visual equivalence, the results obtained with the auditory-visual set (training, equivalence, sorting) were quite superior to those obtained with the visual-visual set. Only 2 participants labeled the stimuli of the auditory-visual set with the name of 
the corresponding sample. The other 3 participants named the stimuli of both sets with familiar labels. These and previously obtained findings (Lazar, Davis-Lang, \& Sanchez, 1984; Sidman, Cresson, Willson-Morris, 1974; Sidman, Kirk, and Willson-Morris, 1985; Sidman \& Tailby, 1982), led to the conclusion that labeling same-class stimuli with a common name is not a sufficient or necessary condition for equivalence class formation (Sidman et al., 1986).

The results of these two studies, however, could raise a number of questions. First, the superior performances obtained with the auditoryvisual set might not be related to the nature of the samples, but to the discriminability of the comparisons. In the study by Green (1990), two comparisons of the visual-visual set consisted of similar forms differing in left-right orientation (< vs. >). Studies by Davidson (1935), Huttenlocher (1967), Rudel and Teuber (1963), Smeets, Lancioni, and Striefel (1991), and Wohlwill and Wiener (1964) have shown that children find left-right orientations more difficult to discriminate than up-down orientations (e.g., $M$ vs. W) or forms (V vs. W). Persons with mental retardation might be expected to have similar difficulties during training and testing. If correct, this problem could have been prevented, by counterbalancing the stimuli across sets.

Second, it is not clear why the differential effects were only evident in persons with mental retardation. If, as has been suggested (Green, 1990; Sidman \& Cresson, 1973; Stromer \& MacKay, 1996), the rapid formation of auditory-visual classes stems from the preponderance of auditoryvisual stimulus relations during early childhood and initial academic instruction, one should expect 5-year-old children to have more difficulties forming visual-visual classes than adults with mild mental retardation, many of whom are capable of reading instructions and capable of holding semi-skilled positions. Given that in the Sidman et al. (1986) study only 2 children were used, replication research with larger numbers of same-age children would seem desirable.

Finally, the naming test may not be an adequate procedure for assessing the relationship between naming and equivalence (Horne \& Lowe, 1996; Stoddard \& Mcllvane, 1986; Stromer \& MacKay, 1996). Even if participants label same-class stimuli with a common name, it cannot be assumed that these responses were functional during the original formation of the equivalence relations. Horne and Lowe (1996) proposed, therefore, that instead of presenting an oral naming test after the completion of the match-to-sample tasks, recordings should be made of the spontaneous verbalizations during these tasks. Unfortunately, the few studies in which collateral naming was recorded show little consistency. In the research reviewed by Horne and Lowe (1996), all 29 children who were trained on visual-visual matching tasks spontaneously named the individual stimuli. Of these children who passed the equivalence test, 17 had intraverbally named the correct sample-comparison pairs during training. These observations differ markedly from those from other studies (Boelens, Van den Broek, \& Klarenbosch, 2000; Goyos, 2000; 
Green, 1990) in which most children failed to name or did not consistently name the stimuli.

The present study was designed to address these three issues. The procedures were basically the same as in the Green (1990) study except that (a) preschool children served as participants, (b) the stimuli that served as comparisons during the baseline training were counterbalanced across sets, and (c) spontaneous naming responses were recorded during all arbitrary matching trials. Would the superiority of any one set be a function of the discriminability of the stimuli? If not, would the children's performances be similar to those obtained with the intellectually handicapped adults used in previous research (Green, 1990; Sidman et al., 1986)? If so, would the present findings lend support for the position that the class-consistent test performances, notably equivalence and sorting, result from naming?

\section{Method}

\section{Children, Adults, and Setting}

Sixteen 5-year-old children, 9 boys and 7 girls, participated. The children were assigned to four conditions, four in each condition. The age (years and months) and sex of each child are listed in Table 1. The children participated with parental consent and on a voluntary basis. According to the teachers, none of the children had participated in experimental research before.

Table 1

Age (years and months) and Sex of Children

\begin{tabular}{|c|c|c|c|c|c|c|c|c|c|}
\hline \multicolumn{2}{|c|}{$\begin{array}{c}\text { Condition } 1 \\
\text { Children Age Sex }\end{array}$} & \multicolumn{3}{|c|}{$\begin{array}{c}\text { Condition } 2 \\
\text { Children Age Sex }\end{array}$} & \multicolumn{2}{|c|}{$\begin{array}{c}\text { Condition } 3 \\
\text { Children Age Sex }\end{array}$} & \multicolumn{3}{|c|}{$\begin{array}{c}\text { Condition } 4 \\
\text { Children Age Sex }\end{array}$} \\
\hline 1 & $5 ; 6 \mathrm{~F}$ & 5 & & $M$ & 9 & $5 ; 7 \mathrm{M}$ & 13 & $5 ; 5$ & $M$ \\
\hline 2 & $5 ; 7 \quad M$ & 6 & $5 ; 3$ & M & 10 & $5 ; 6 \mathrm{~F}$ & 14 & $5 ; 3$ & $\mathrm{~F}$ \\
\hline 3 & $5 ; 2 \mathrm{M}$ & 7 & $5 ; 6$ & $\mathrm{~F}$ & 11 & $5 ; 5 \mathrm{~F}$ & 15 & $5 ; 2$ & $\mathrm{~F}$ \\
\hline 4 & $5 ; 7 \quad M$ & 8 & $5 ; 6$ & $\mathrm{~F}$ & 12 & $5 ; 2 \mathrm{M}$ & 16 & $5 ; 5$ & M \\
\hline
\end{tabular}

The children were seen in a quiet room of the school building. The sessions were conducted individually, once a day, and lasted 15 to 30 $\mathrm{min}$. The children required 7 to 13 sessions over a period of 2 to 3 weeks. An adult female served as experimenter. The experimenter and child were seated at the same table facing one another. Prior to her participation in this study, the experimenter had received extensive training on the correct execution of the procedures with special emphasis on the prevention of any cues (facial expression, eye darting) that could influence the child's performance. During the training trials, the experimenter looked at the child's face when giving instructions and delivering programmed consequences. During the remainder of these trials (i.e., when presenting stimuli and while the children responded), the experimenter gazed at the lower edge of the stimulus card. Precautions 

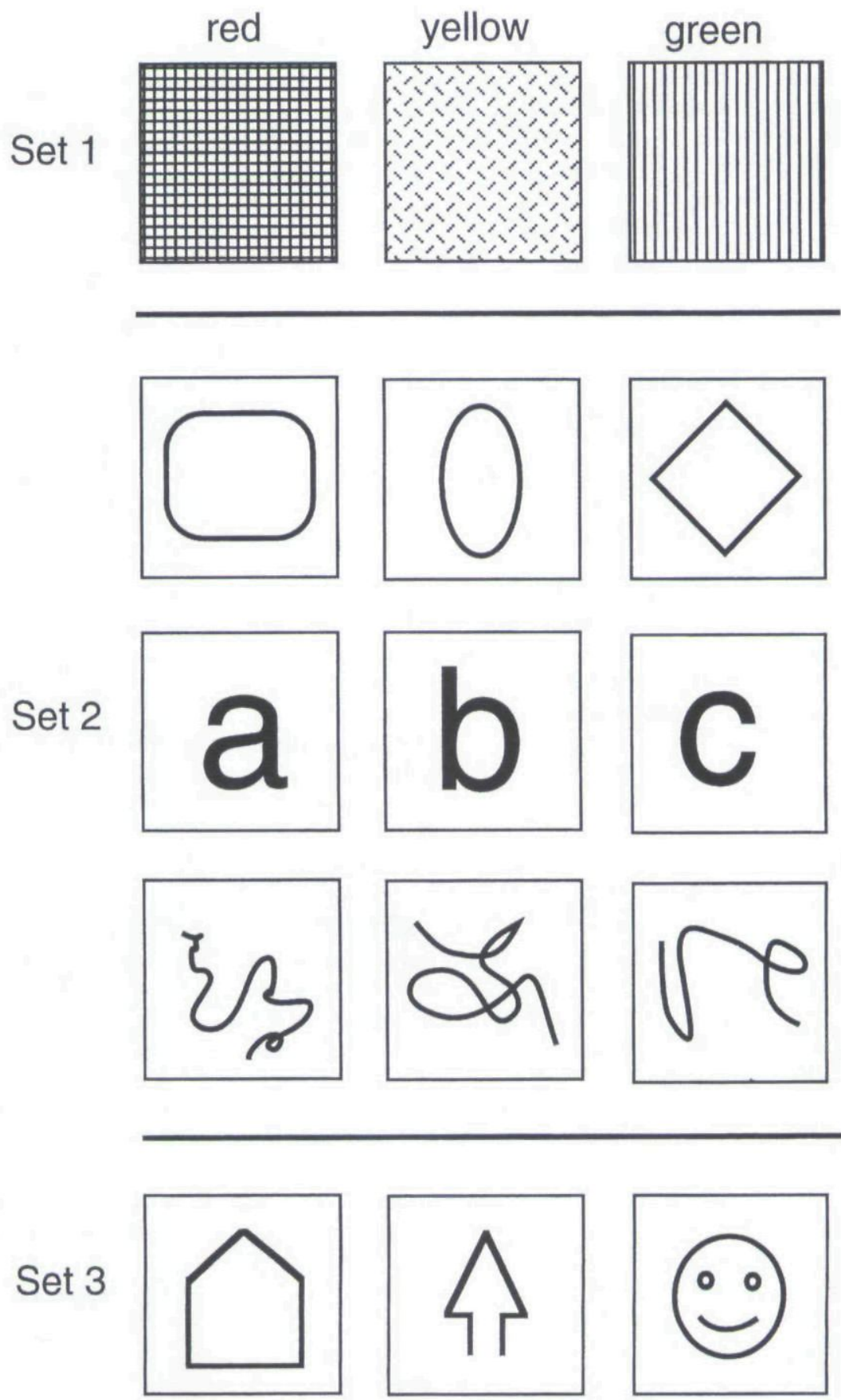

Figure 1. Stimuli used during the introductory phases of the experiment. 
were taken to prevent the children from observing the experimenter's recordings on the data sheets. Six other adults served as reliability observers, one at the time. The reliability observer was present in the same room but situated such (behind and slightly to the right or left of the child) that he/she could clearly observe the child's responses, but not the experimenter's data sheet.

\section{Stimuli, Tasks, and Materials}

Four sets of visual stimuli $(4.5 \times 4 \mathrm{~cm})$ were used. Set 1 consisted of color patches, Set 2 of geometrical forms, letters, and scribble-type configurations, and Set 3 of schematic drawings of familiar objects. These three sets (see Figure 1) were used only during the introductory phases of the experiment. Set 4 consisted of abstract forms similar to those used by Green (1990). These stimuli (see Figure 2) are identified by alphanumeric codes (e.g., A1, B2) and were used only during the experimental phases of the program (training and testing). Furthermore, three auditory stimuli were used, "Ia" (N1), "voo" (N2), and "kee" (N3). These stimuli were dictated by the experimenter.

During the naming and sorting tests, the stimuli were presented individually, each on a $4.5-\times 4.5-\mathrm{cm}$ card. During the match-to-sample tasks, multiple stimuli were presented on laminated white cards $(14.5 \mathrm{x}$ $21 \mathrm{~cm}$ ). Each card showed three comparisons near the bottom of the card, and a sample at the top center (visual-visual tasks) or no visual sample (auditory-visual tasks).

Additional stimuli consisted of a transparent glass tube with a mark and a jar filled with beads. Fifty beads were needed to fill the vase up to the mark.

\section{Trial Blocks, Response Recording, Feedback, and Criteria}

Each block of match-to-sample tasks consisted of $6,9,12$, or 18 trials. Same samples were not used on more than two consecutive trials. The locations of the comparisons varied unsystematically over trials. Each comparison appeared an equal number of times as correct.

During match-to-sample tasks, a response was recorded correct when a child selected a comparison of the same designated class as the sample. All other responses were recorded incorrect. During the arbitrary matching trials, the experimenter also recorded any unsolicited verbalizations that could be considered a naming response (e.g., "What a funny arrow") or as an imitation of any of the three dictated samples (e.g., "voo") that was used during the current trial or during a previous trial. If, during a trial, the child gave multiple names or repeated the same name (e.g., "la-la-la"), which very seldom occurred, only the first name was recorded.

During training, correct responses were followed by verbal praise and the delivery of a bead ("Good, take a bead"). Incorrect responses were followed by "Wrong! No bead." If during a session, the number of earned beads reached the mark, the experimenter interrupted the session, emptied the tube, gave the child the opportunity to exchange the beads for a color 
1
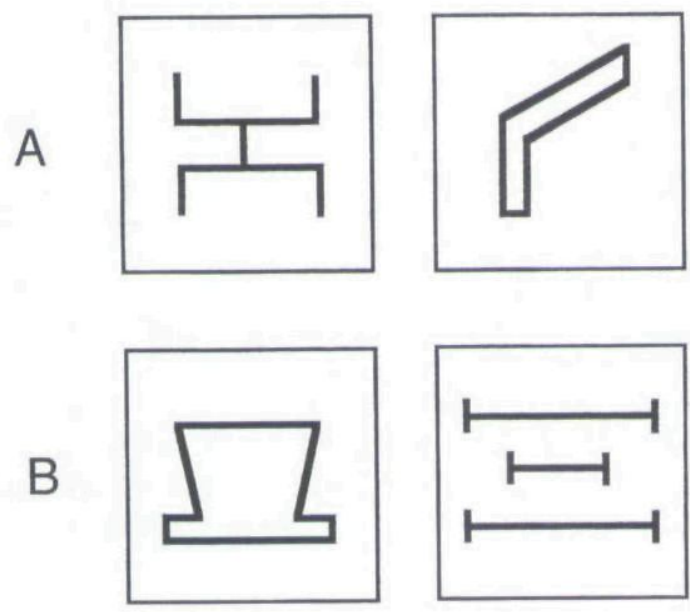

B
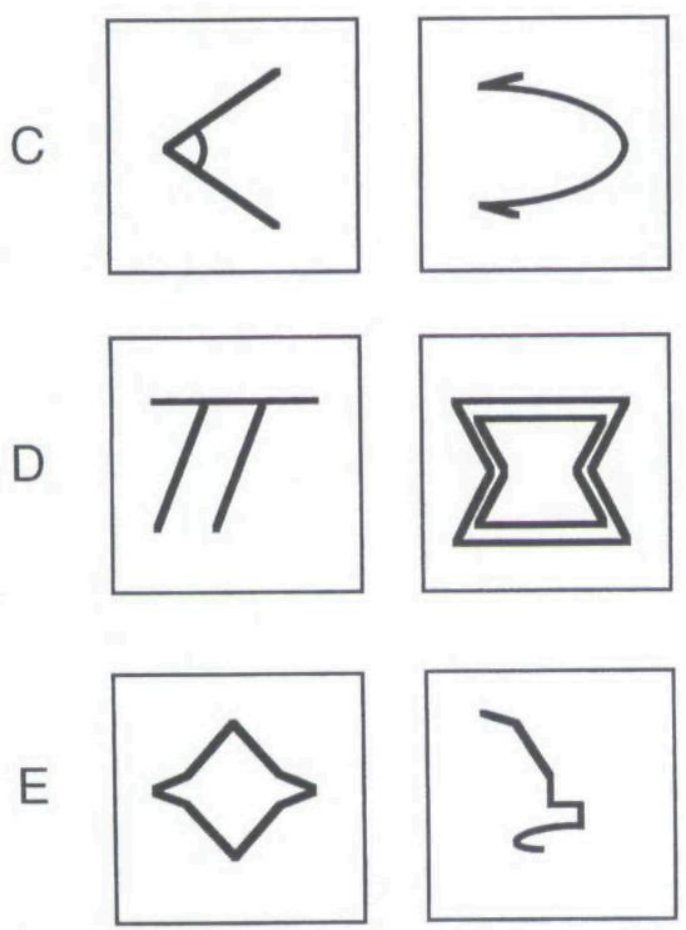
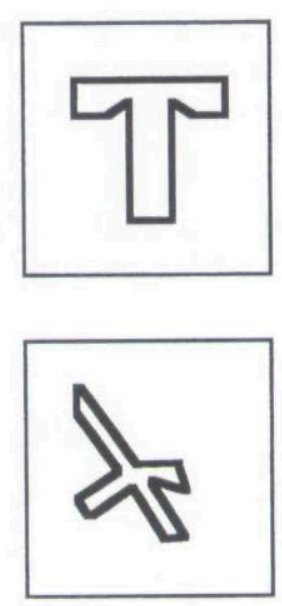

3
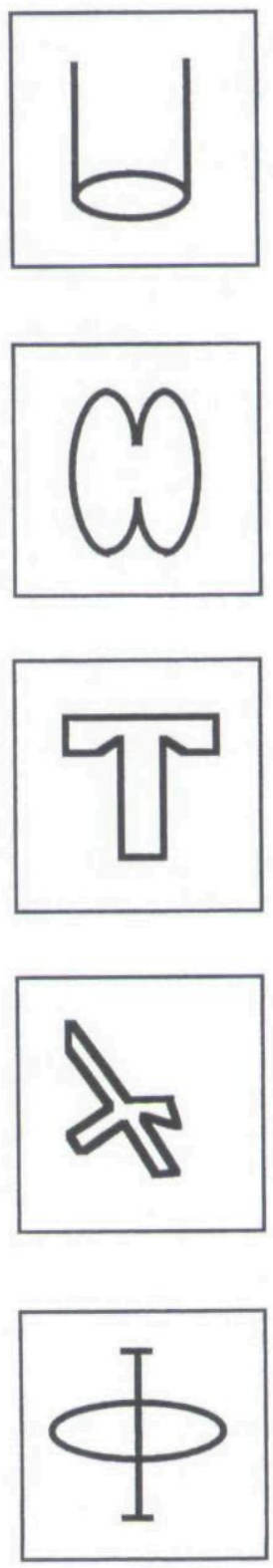

Figure 2. Experimental stimuli.

picture (soccer player, racing car, cartoon character, or animal), and resumed the session. Test trials were followed by no feedback except that, after the completion of each trial block, the experimenter gave the child 12 beads irrespective of his/her performance. 
During match-to-sample training, mastery criterion was set at all trials correct for blocks of 6 and 9 trials, and at least $\mathrm{N}-1$ trials correct for blocks of 12 or 18 trials. During match-to-sample tests, mastery criterion was set at $\mathrm{N}-1$ trials correct in one block, or at $\mathrm{N}-2$ trials correct in each of two consecutive blocks of 18 trials.

\section{General Experimental Design}

Four conditions were used. The training and test phases of each condition are listed in Tables 2 and 3. All four conditions started with the same three introductory phases including a reflexivity test. Then, the children of Conditions 1 and 2 were trained on visual-visual match-tosample tasks, A-B, A-C in Condition 1, and A-D and A-E in Condition 2. Thereafter, they received the opportunity to (a) show these performances under testing conditions (baseline test), (b) demonstrate equivalence and symmetry, (c) name the visual stimuli, and (d) sort the stimuli according to class membership. At that point, the auditory-visual sequence was introduced: testing reflexivity, training of auditory-visual baseline tasks ("N"-D, "N"-E in Condition 1, "N"-B, "N"-C in Condition 2), followed by baseline, equivalence, naming, and sorting tests. Conditions 3 and 4 were the same as Conditions 1 and 2, respectively, except that the auditory-visual tasks were trained first.

\section{Conditions 1 and 2}

Phase 1: Pretraining sorting. These tasks served to prepare the children for the sorting tasks that were used during Phases 11 and 19 (see below). At first, the children were trained on a color-sorting task.

Table 2

Test and Training Sequence in Conditions 1 and 2

\begin{tabular}{|c|c|c|c|c|c|}
\hline \multicolumn{2}{|c|}{$\begin{array}{l}\text { Condition } 1 \\
\text { Phases Training/Test }\end{array}$} & Tasks/Stimuli & \multicolumn{2}{|c|}{$\begin{array}{l}\text { Condition } 2 \\
\text { Phases Training/Test }\end{array}$} & \multirow{2}{*}{ Tasks/Stimuli } \\
\hline \multicolumn{5}{|c|}{ Visual-Visual } & \\
\hline & Pretraining sorting & $\begin{array}{l}\text { Colors and forms } \\
\text { (Sets } 1 \text { and 2) }\end{array}$ & 1 & Pretraining sorting & $\begin{array}{l}\text { Colors and forms } \\
\text { (Sets } 1 \text { and } 2 \text { ) }\end{array}$ \\
\hline 2 & Training identity matching & Forms (Set 3) & 2 & Training identity matching & Forms (Set 3) \\
\hline 3 & Reflexivity test & $A-A, B-B, C-C$ & 3 & Reflexivity Test & $A-A, D-D, E-E$ \\
\hline $4-6$ & Baseline training & $A \cdot B, A-C$ & $4-6$ & Baseline training & $A-D, A-E$ \\
\hline 7 & Baseline test & $A-B, A-C$ & 7 & Baseline test & $A-D, A-E$ \\
\hline 8 & Equivalence test & B-C, C-B & 8 & Equivalence test & $D-E, E \cdot D$ \\
\hline 9 & Symmetry Test & B-A, C-A & 9 & Symmetry test & D-A, E-A \\
\hline 10 & Naming test & All stimuli & 10 & Naming test & All stimuli \\
\hline 11 & Sorting test & All stimuli & 11 & Sorting test & All stimuli \\
\hline \multicolumn{6}{|c|}{ Auditory-Visual } \\
\hline 12 & Reflexivity test & $D-D, E-E$ & 12 & Reflexivity test & $\mathrm{B} \cdot \mathrm{B}, \mathrm{C}-\mathrm{C}$ \\
\hline 13-15 & Baseline training & "N"-D, "N"-E & 13-15 & Baseline training & "N"-B, "N"-C \\
\hline 16 & Baseline test & "N"-D, "N"-E & 15 & Baseline test & "N"-B, "N"-C \\
\hline 17 & Equivalence test & $D-E, E-D$ & 16 & Equivalence test & $B \cdot C, C-B$ \\
\hline 18 & Naming test & All stimuli & 18 & Naming test & All stimuli \\
\hline 19 & Sorting test & All stimuli & 19 & Sorting test & All stimuli \\
\hline
\end{tabular}


Table 3

Test and Training Sequence in Conditions 3 and 4

\begin{tabular}{|c|c|c|c|c|c|}
\hline \multicolumn{2}{|c|}{$\begin{array}{l}\text { Condition } 3 \\
\text { Phases Training/Test }\end{array}$} & Tasks/Stimuli & \multicolumn{2}{|c|}{$\begin{array}{l}\text { Condition } 4 \\
\text { Phases Training/Test }\end{array}$} & \multirow{2}{*}{ Tasks/Stimuli } \\
\hline \multicolumn{5}{|c|}{ Auditory-Visual } & \\
\hline 1 & Pretraining sorting & $\begin{array}{l}\text { Colors and forms } \\
\text { (Sets } 1 \text { and 2) }\end{array}$ & 1 & Pretraining sorting & $\begin{array}{l}\text { Colors and forms } \\
\text { (Sets } 1 \text { and 2) }\end{array}$ \\
\hline 2 & Training identity matching & Forms (Set 3) & 2 & Training identity matching & Forms (Set 3) \\
\hline 3 & Reflexivity test & $\mathrm{B}-\mathrm{B}, \mathrm{C}-\mathrm{C}$ & 3 & Reflexivity Test & $D-D, E-E$ \\
\hline 4.6 & Baseline training & "N"-B, "N"-C & $4-6$ & Baseline training & $" N "-D, " N " \cdot E$ \\
\hline 7 & Baseline test & $" N "-B, " N "-C$ & 7 & Baseline test & $" N " D,{ }^{\prime \prime} N "-E$ \\
\hline 8 & Equivalence test & $B-C, C \cdot B$ & 8 & Equivalence test & $D-E, E-D$ \\
\hline 9 & Naming test & All stimuli & 9 & Naming test & All stimuli \\
\hline 10 & Sorting test & All stimuli & 10 & Sorting test & All stimuli \\
\hline \multicolumn{6}{|c|}{ Visual-Visuall } \\
\hline 11 & Reflexivity test & $A-A, D-D, E-E$ & 11 & Reflexivity test & $A-A, B-B, C-C$ \\
\hline $12-14$ & Baseline training & $A-D, A-E$ & $12-14$ & Baseline training & $A-B, A-C$ \\
\hline 15 & Baseline test & $A-D, A-E$ & 15 & Baseline test & $A-B, A-C$ \\
\hline 16 & Equivalence test & $D \cdot E, E \cdot D$ & 16 & Equivalence test & $B-C, C-B$ \\
\hline 17 & Symmetry test & $D \cdot E, E \cdot A$ & 17 & Symmetry test & B-A, C-A \\
\hline 18 & Naming test & All stimuli & 18 & Naming test & All stimuli \\
\hline 19 & Sorting test & All stimuli & 19 & Sorting test & All stimuli \\
\hline
\end{tabular}

Stimuli of Set 1 were used (see Figure 1). On each trial, the experimenter presented an unorganized pile of nine color cards, three red, three yellow, and three green cards, said, "Look, I am going to make piles of pictures that go together," modeled the correct performance (i.e., made three piles of same color cards), and gave the child the opportunity to do the same ("Can you do that too?"). This task was repeated until the child sorted all stimuli correctly (one trial).

Then a form-sorting task was introduced. During this task, the stimuli of Set 2 were used. The procedures were the same except that the experimenter no longer modeled the correct performance. The task was scored correct when a child made three piles of three cards each, one of geometric forms, one of letters, and one of scribbles. Children who failed this task twice were scheduled to be excluded from the experiment, which never occurred.

Phase 2: Training identity matching. This phase served to familiarize the children with the match-to-sample task. The stimuli of Set 3 were used. Blocks of nine identity-matching trials were used, three on each task (househouse, arrow-arrow, face-face). During the first two trials, the experimenter pointed to the sample, while saying, "Can you show me a picture that goes with this?" During the following trials, this instruction was omitted.

Phase 3: Testing reflexivity. This test assessed if the children matched the stimuli of the visual-visual set (see Figure 2) without training. The experimenter introduced this test with the instruction, "Now I would like to see if you can play the game without me telling you whether you are right or wrong. I also take away the beads. You will get the beads after we finish this." The test consisted of 18 trials, 6 A-A trials mixed with $6 \mathrm{~B}-\mathrm{B}$ and $6 \mathrm{C}-\mathrm{C}$ trials (Condition 1) or with $6 \mathrm{D}-\mathrm{D}$ and $6 \mathrm{E}-\mathrm{E}$ trials (Condition 2). 
Phases 4-6: Baseline training. In Condition 1, three A-B and three A$C$ relations were trained. The $A-B$ relations were trained in Phase 4 . Three steps were used. In Step 1, the A1-B1 and A2-B2 relations were trained. Blocks of 20 trials were used, 2 demonstration trials followed by 18 nohelp trials (9 A1-B1 trials quasi-randomly mixed with 9 A2-B2 trials). On each demonstration trial, the experimenter pointed to the sample while saying, "Look here," pointed to the designated correct comparison and said, "Point to this picture." When introducing the first no-help trial, the experimenter said, "Now, you have to find the correct picture on your own." Children who demonstrated criterion performance (at least 17/18 no-help trials correct) proceeded to Step 2. The procedures were the same as in Step 1 except that the A3-B3 relations were also trained and no demonstration trials were used. Each block consisted of 18 trials, 9 A3-B3 trials, mixed with 9 A1-B1 and A2-B2 trials. Step 3 was the same as Step 2, but with 6 trials on each task.

In Phase 5, the A-C relations were trained. The procedures were the same as for the A-B training (Phase 4) except that each block of $18 \mathrm{~A}-\mathrm{C}$ trials was followed by a block of 6 A-B trials. In Phase 6 , each block consisted of 9 A-B trials quasi-randomly mixed with 9 A-C trials (mixed baseline training). In Condition 2, the procedures were the same except that $A-D$ and $A-E$ relations were trained.

Phase 7: Baseline test. This test assessed if the baseline performances remained intact under testing conditions. The procedures were the same as in Phase 6 (mixed training) but without differential feedback. The experimenter introduced this phase by saying, "Now I would like to see if you can play this game also without me telling you whether you were right or wrong. I also take away the beads. You will get the beads after we finish this."

Phase 8: Equivalence test. The procedures were the same as during the baseline test (Phase 7) except that the children were now given the opportunity to match same-class B and C stimuli (B-C, C-B) in Condition 1, and same-class $D$ and $E$ stimuli (D-E, E-D) in Condition 2. Children who demonstrated criterion performance during the first or second presentation proceeded to Phase 9 (symmetry test). Those who failed the test, returned to Phases 6 and 7 (mixed baseline training, baseline test), at which point they received the equivalence test again (maximum of two presentations). Then they proceeded to Phase 9 irrespective of their performance.

Phase 9: Symmetry test. Class-consistent B-A, C-A and D-A, E-A performances were assessed in Conditions 1 and 2, respectively. All children received a maximum of two test presentations. Children who showed symmetry and had also evidenced equivalence in Phase 8, proceeded to Phase 10 (naming test). Children who passed the symmetry test but had failed the equivalence test in Phase 8, now received the equivalence test again (maximum of two presentations). Those who failed the symmetry test returned to Phases 6 and 7 (mixed baseline training, baseline test) at which point they received the symmetry test again (maximum of two presentations). Then they proceeded to Phase 10, irrespective of their performance on the symmetry test. 
Phase 10: Naming test. This test assessed if the children labeled the A, B, and C stimuli (Condition 1) or A, D, and E stimuli (Condition 2) each with a different familiar name (e.g., "star," "butterfly") or whether they gave same-class stimuli a common name. All stimuli were presented once. On each trial, the experimenter presented a stimulus (e.g., A1), and asked, "What do you call this?"

Phase 11: Sorting test. This test provided an additional indication for class formation (Green, 1990; Pilgrim \& Galizio, 1996). All children received three presentations. On each presentation, the experimenter placed an unorganized pile of nine stimulus cards on the table and said, "Make piles of pictures that go together."

Phases 12-19. These phases were the same as Phases 3 to 12, but with dictated names as samples (baseline training) and no symmetry test. In Phase 12, the children received identity match-to-sample tests, D-D and $\mathrm{E}-\mathrm{E}$ (Condition 1) or B-B and C-C (Condition 2). Phases 13 to 16 were directed at training and testing novel baseline relations with dictated words as samples, "N"-D, "N"-E in Condition 1, and "N"-B, "N"-C in Condition 2. In Phase 17, the children received the opportunity to match visual stimuli that had been related to a same dictated word, D-E, E-D in Condition 1, and B-C, C-B in Condition 2 (equivalence test). Finally, they received a naming test in Phase 18, and a sorting test in Phase 19.

\section{Conditions 3 and 4}

The procedures were the same as Conditions 1 and 2, respectively, except that the training and testing of auditory-visual equivalence preceded the training and testing of visual-visual equivalence.

\section{Interobserver Agreement}

Interobserver agreement data were collected on $13 \%$ of the pretraining trials, $28 \%$ of the match-to-sample training trials, $43 \%$ of the match-to-sample test trials, $40 \%$ of the naming-test trials, and on $47 \%$ of the sorting-test trials. The experimenter and observers agreed on $100 \%$ of all pretraining trials, on $99 \%$ of the match-to-sample training trials, on $99 \%$ of the match-to-sample test trials, and on $100 \%$ of the naming-test and sorting-test trials.

\section{Results}

One child was eliminated from the experiment due to uncooperative behavior and was replaced by another child.

\section{Pretraining, Testing Reflexivity, Training and Testing Baseline}

All children readily learned the pretraining tasks and performed errorlessly on the generalized identity-matching tasks, thereby demonstrating reflexivity (Boelens, 2001; Green, 1990; Sidman et al., 1986). Table 4 shows the numbers of trials to complete the baseline training. All children learned the auditory-visual tasks without requiring 
more than two extra trial blocks (Mean: 155 trials, Range: 144-162). The same applied to the visual-visual tasks, except for Children 3, 4, 13, and 14. These 4 children required 4 to 10 extra blocks to learn these tasks (Mean: 271 trials, Range: 220-330). These temporary difficulties were not related to the training order (before or after auditory-visual training) or age. All children responded accurately during the baseline tests.

Table 4

Required Numbers of Baseline Training Trials

\begin{tabular}{|c|c|c|c|c|c|c|c|c|c|}
\hline & \multicolumn{2}{|c|}{ Visual-Visual } & \multicolumn{2}{|c|}{ Auditory-Visual } & \multirow[b]{2}{*}{ Children } & \multicolumn{2}{|c|}{ Auditory-Visual } & \multicolumn{2}{|c|}{ Visual-Visual } \\
\hline Children & $\begin{array}{l}A-B \\
A-C\end{array}$ & $\begin{array}{l}A-D \\
A-E\end{array}$ & $\begin{array}{l}\text { “N"-D } \\
\text { "N"-E }\end{array}$ & $\begin{array}{l}\text { "N"-B } \\
\text { "N"-C }\end{array}$ & & $\begin{array}{l}\text { "N"-B } \\
\text { "N"-C }\end{array}$ & $\begin{array}{l}\text { "N"-D } \\
\text { "N"-E }\end{array}$ & $\begin{array}{l}A-D \\
A-E\end{array}$ & $\begin{array}{l}A-B \\
A-C\end{array}$ \\
\hline $\begin{array}{c}\text { Contition } 1 \\
1 \\
2 \\
3 \\
4 \\
\text { Mean }\end{array}$ & $\begin{array}{l}144 \\
144 \\
222 \\
312 \\
206\end{array}$ & & $\begin{array}{l}144 \\
144 \\
162 \\
144 \\
149\end{array}$ & & $\begin{array}{c}\text { Condition } 3 \\
9 \\
10 \\
11 \\
12 \\
\text { Mean }\end{array}$ & $\begin{array}{l}162 \\
162 \\
144 \\
144 \\
153\end{array}$ & & $\begin{array}{l}144 \\
162 \\
144 \\
144 \\
149 \\
\end{array}$ & \\
\hline $\begin{array}{l}\text { Condition } 2 \\
5 \\
6 \\
7 \\
8 \\
\text { Mean }\end{array}$ & & $\begin{array}{l}144 \\
162 \\
144 \\
162 \\
153\end{array}$ & & $\begin{array}{l}144 \\
162 \\
162 \\
162 \\
158\end{array}$ & $\begin{array}{c}\text { Condition } 4 \\
13 \\
14 \\
15 \\
16 \\
\text { Mean }\end{array}$ & & $\begin{array}{l}162 \\
144 \\
162 \\
162 \\
159\end{array}$ & & $\begin{array}{l}222 \\
330 \\
162 \\
144 \\
215\end{array}$ \\
\hline
\end{tabular}

\section{Testing Stimulus-Class Formation and Naming}

Tables 5 and 6 show the test results (equivalence, symmetry, naming, sorting) for Conditions 1 and 2, and Conditions 3 and 4 , respectively. The results of the baseline tests are not listed because the children almost always responded accurately. To facilitate the reading of these tables, consider the results of Child 4 (Table 5) in detail. After being trained and tested on the A-B and A-C relations, the child failed both presentations of the equivalence test (B-C, C-B). Then he received review training and testing of the baseline tasks, failed the equivalence test again twice, and received the symmetry test which he passed during the second presentation. At that point he again received and failed the equivalence test twice. During the subsequent naming test, he gave all stimuli familiar names (e.g., A1: "radio," B1: "chair," C1: "leaf"), and failed the sorting test. Then he received baseline training and testing of the "N"-D and "N"-E relations. He failed the equivalence test twice (D-E, E-D), received review training and testing on the baseline tasks, and passed the equivalence test during the second presentation. During the naming test, he labeled the D and E stimuli with familiar names (e.g., D3: "rocket," E3: "circle") and failed the sorting test.

Equivalence and symmetry. All 16 children (100\%) demonstrated auditory-visual equivalence, almost all of them immediately. Of these 16 


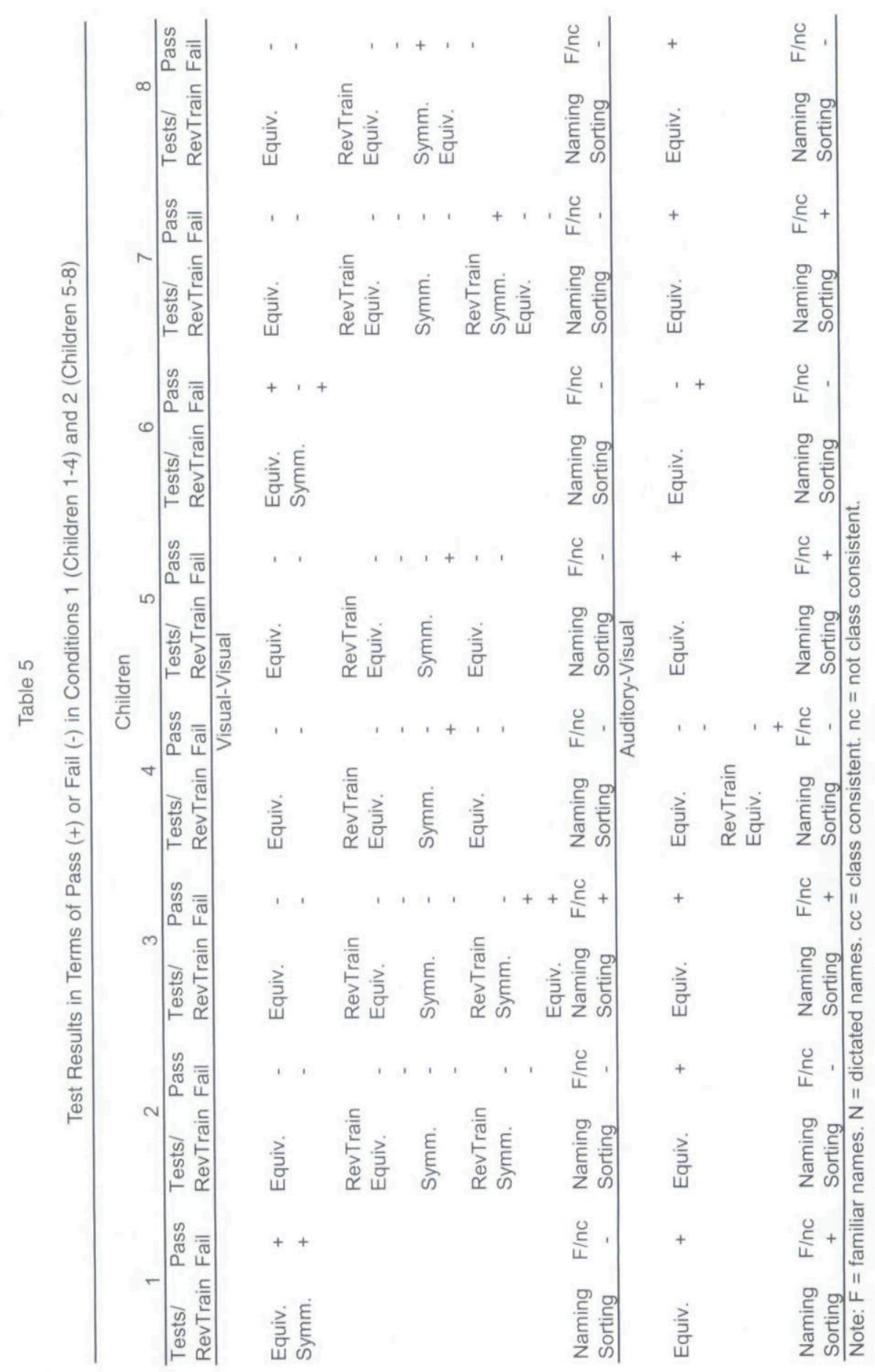




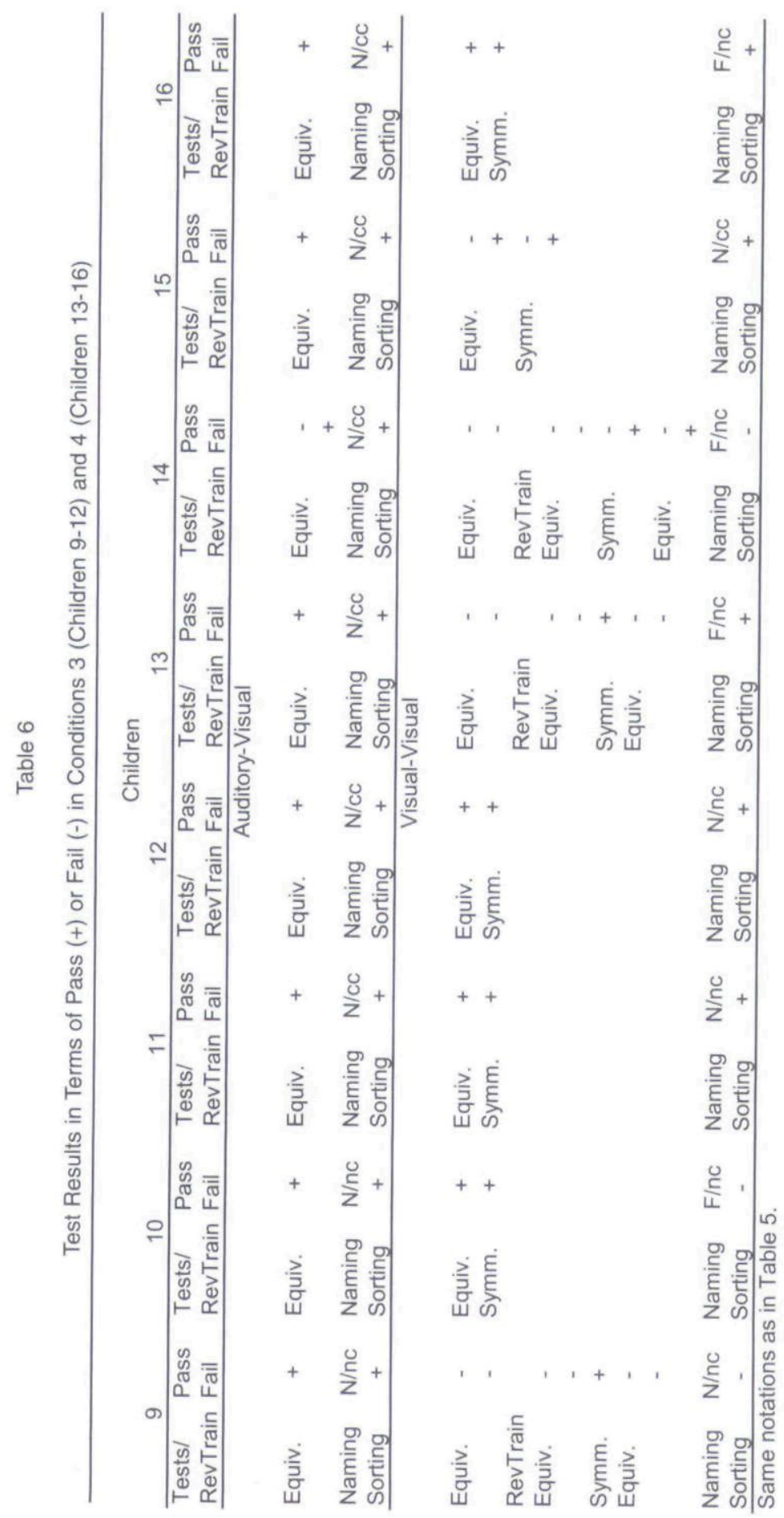


children, 9 (56\%) evidenced visual-visual equivalence, 3 (33\%) before (Conditions 1 and 2), and $6(67 \%)$ after auditory-visual equivalence (Conditions 3 and 4). Except for Child 2, all children evidenced symmetry although some of them, notably in Conditions 1 and 2, only after repeated testing and review training.

Naming tests. Class-consistent naming never occurred when the visual-visual set was introduced first (Conditions 1 and 2). During these conditions, all children labeled the stimuli of the visual-visual set and of the auditory-visual set with familiar names. When the auditory-visual set was introduced first (Conditions 3 and 4), 6 children (11, 12, 13, 14, 15, 16) named the stimuli of that set class-consistently, that is, all class-1 stimuli "la," all class-2 stimuli "voo," and all class-3 stimuli "kee." One of these children (15) also did so with the stimuli of the subsequent visualvisual set even though these names were not used during training. In all other instances, the stimuli of the auditory-visual and visual-visual sets were indiscriminately labeled "la," "voo," or "kee," or given familiar names. Thus, with one exception, class-consistent naming occurred only with stimuli of the auditory-visual set and exclusively when that set was used first.

Sorting tests. Class-consistent sorting was seen 18 times, once after failing the equivalence test (Child 13), and 17 times after passing that test. These performances were seen less often after visual-visual training than after auditory-visual training, but only when these conditions were used first. All 8 children who received the auditory-visual training first sorted according to classes. Of the 8 children who received the visual-visual training first, only 1 sorted according to classes. When the two conditions were presented last, 4 of the 8 who had received auditory-visual training and 5 of the 8 children who had received visualvisual training sorted according to classes.

\section{Spontaneous Naming}

Table 7 shows the frequencies and percentages of spontaneous naming responses (dictated vs. familiar names) emitted during baseline training, baseline tests, and tests for equivalence and symmetry. Naming varied considerably between stimulus sets, training and testing, and children. During the 5172 trials that the visual-visual sets were used, only four naming responses were made, all by Child 13 during baseline training. During the 3228 trials that the auditory-visual sets were used, 5 children $(1,11,12,15,16)$ never emitted a naming response. The other 11 children each named these stimuli 1 to 92 times (Mean: 23). Together, these children made a total of 249 naming responses, 218 during baseline training, 28 during baseline tests, and 3 during the equivalence tests. With one exception (Child 13), all these verbalizations involved the labels "la," "voo," and "kee." 


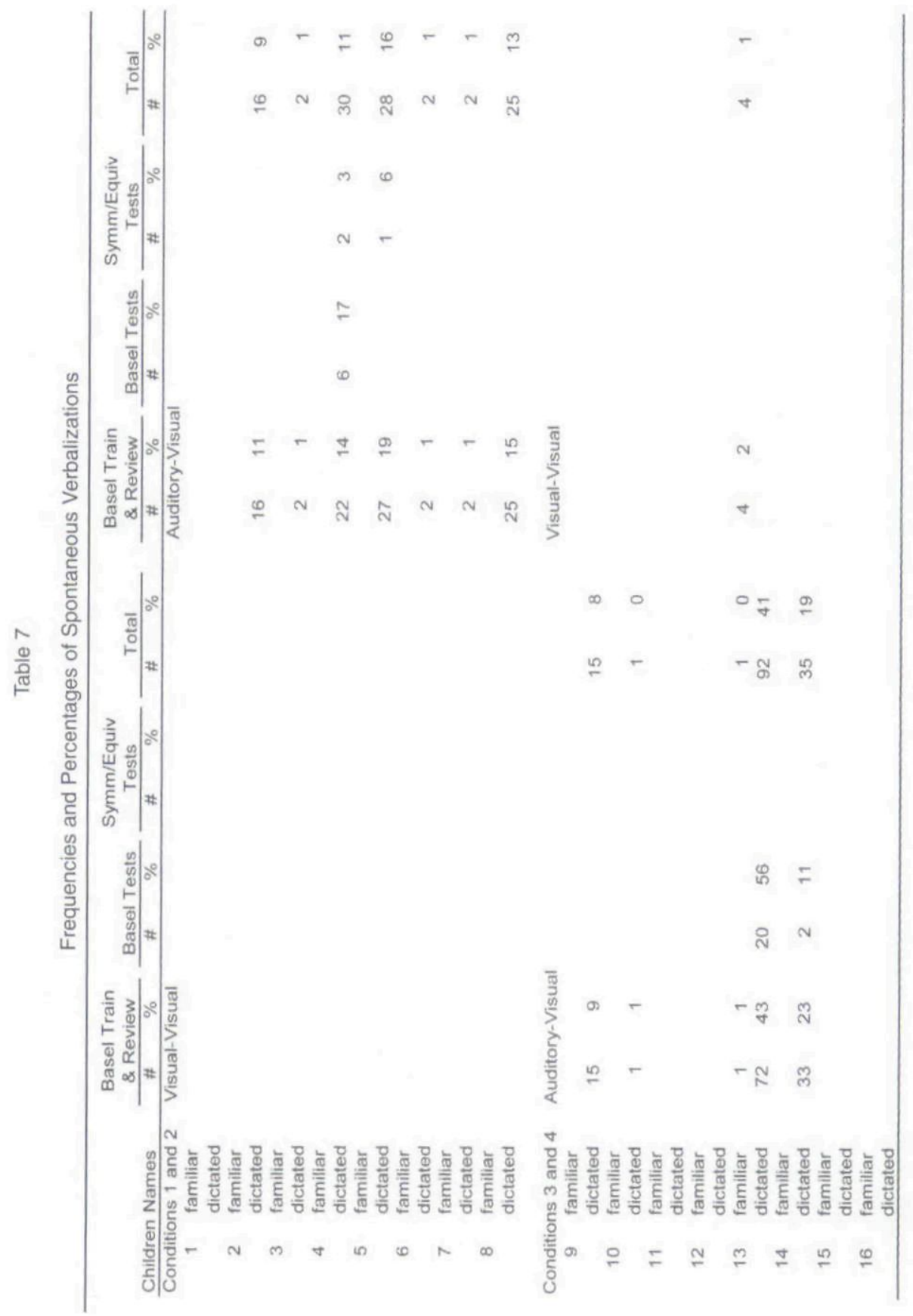




\section{Discussion}

Match-to-sample training with auditory samples was a far more effective procedure for establishing derived class-consistent performances than training with visual samples. This discrepancy was evident, albeit in various degrees, in all phases of the program. During baseline training, 4 children required considerably more trials to learn the visual-visual tasks than the auditory-visual tasks. All 16 children (100\%) demonstrated equivalence with the stimuli of auditory-visual sets whereas only 9 children $(56 \%)$ did so with the stimuli of the visual-visual sets. This discrepancy becomes even more pronounced when also considering the moment of occurrence. Auditory-visual equivalence was almost always evident during the first test presentation while visual-visual equivalence frequently required retesting and review training. Moreover, visual-visual equivalence frequently did not occur unless auditory-visual equivalence ( 6 children) or symmetry ( 2 children) had been demonstrated before. Finally, class-consistent sorting was seen 12 times (75\%) with stimuli of the auditory-visual sets and only 6 times $(38 \%)$ with stimuli of the visualvisual sets. For an overview of the major data, see Table 8 . These findings are highly consistent with those reported by Sidman et al. (1986) and Green (1990). They show that the superior auditory-visual performances reported in these studies were not related to the discriminability of stimuli and are not restricted to persons with mental retardation.

Table 8

Instances of Class-Consistent Performance During Equivalence, Symmetry, Naming, and Sorting Tests, and Numbers of Spontaneous Naming Responses

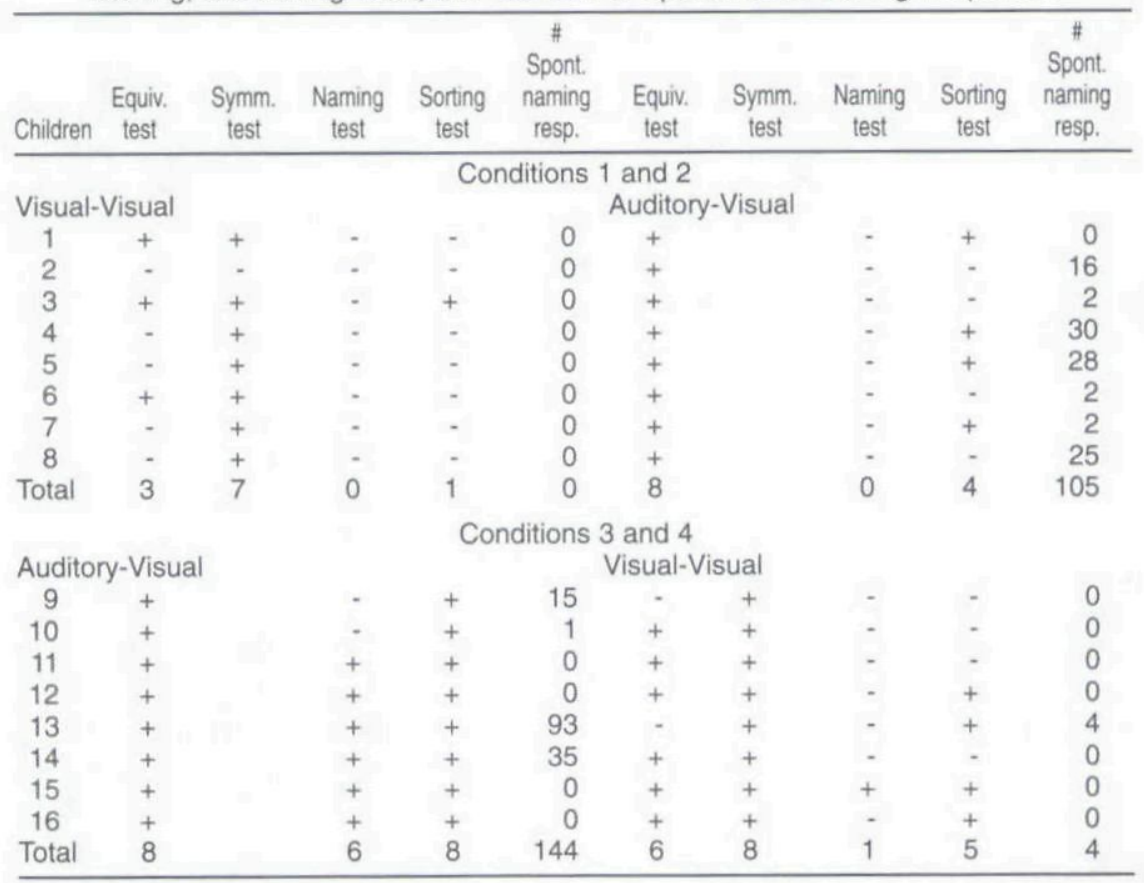


The equivalence and sorting performances were not consistent with the observations and predictions reported in studies by proponents of the naming account. Consider the following analyses. According to Horne and Lowe (1996), children who spontaneously name the stimuli during the baseline trials, notably those who do so in a class-consistent fashion, should learn the baseline tasks faster and more readily evidence classconsistent performances (equivalence, sorting) than children who don't name. The present findings do not support this position for the visual-visual sets because, except for Child 13, none of the children ever named these stimuli. The same applied to the auditory-visual sets. Five children $(1,11$, $12,15,16)$ never mentioned any names, yet they all learned the baseline tasks just as fast as the other children, and passed the equivalence and sorting tests. These findings, therefore, do not indicate that spontaneous naming is a predictor or precondition for stimulus-class formation.

Given these negative results, we analyzed whether the matching performances (baseline, equivalence) and sorting performances could be related to the verbal labels given during the naming test. Although, as pointed out before, the usefulness of this test has been questioned, one might argue that the names given during that test were the same as those that were used, albeit covertly, during the matching tasks. First, we assessed if the occurrences of equivalence and class-consistent sorting corresponded with class-consistent naming. Again, no such relationship could be established, not with the visual-visual sets because, except for Child 15, none of the children labeled these stimuli class-consistently, and also not with the auditory-visual sets; only 6 children named these stimuli class-consistently, yet all 16 children evidenced equivalence, 12 of whom also showed class-consistent sorting.

Subsequently, we assessed if equivalence and class-consistent sorting could have resulted from intraverbal naming (Horne \& Lowe, 1996). This process, it is argued, requires participants to label each stimulus consistently with a different name (e.g., name A1 always "elephant," B1 always "wheel," and $\mathrm{C} 1$ always "letter") and the contingencies induce the participants to (covertly) say the names of the samples and the designated correct comparisons (e.g., A1-B1: "elephant - letter," A1-C1: "elephant - wheel"). To perform this analysis with the visual-visual sets, the children were divided into two groups. One group consisted of 7 children $(2,3,5,7,13,14,16)$. These children consistently gave each stimulus a different name and will be referred to as the "consistent group." These performances permitted equivalence formation on the basis of intraverbal naming. The other group consisted of 8 children $(1,4,6,8,9,10,11,12)$. These children repeatedly gave same stimuli different names (e.g., named A1 "elephant," "button," or "car") or gave same names to different stimuli irrespective of class membership (e.g., labeled A1, A2, E1, F1, F3: "Voo") and will be referred to as the "inconsistent group." These performances did not permit intraverbal naming based equivalence formation. Child 15 was not included in this analysis because he might be considered a special case. Again, no relationship could be established. Of the consistent group, 3 children 
showed visual-visual equivalence (43\%), and 3 class-consistent sorting (43\%). Of the inconsistent group, 5 children showed equivalence $(63 \%)$ and 2 class-consistent sorting $(25 \%)$. Similar findings were obtained with the auditory-visual sets. Of the 10 children who gave same-class stimuli different names, $4(1,8,9,10)$ did so in an inconsistent fashion, yet all of them evidenced auditory-visual equivalence, 3 of them also class-consistent sorting. Collectively, these findings indicate that irrespective of whether the recordings were made during or after the matching tasks, overt naming and stimulus class formation occurred independently from one another (Boelens et al., 2000; Green, 1990; Lazar et al., 1984; Sidman \& Tailby, 1982; Sidman et al., 1974, 1986). The reason for the superiority of the auditory-visual training therefore probably lies elsewhere.

The present findings, however, could be criticized for the fact that many of our 5-year-olds failed to demonstrate visual-visual equivalence. Previous studies, including some with tabletop settings, have shown that children of that age level and even much younger children readily demonstrate visual-visual equivalence (e.g., Barnes, Browne, Smeets, \& Roche, 1995; Barnes et al., 1990; Carpentier, Smeets, \& Barnes-Holmes, 2002; Devany et al., 1986; Lazar et al., 1984; Sidman et al., 1986; Smeets \& Barnes-Holmes, 2003; Whetherby, Karlan, \& Spradlin, 1983; but see Saunders, Drake, \& Spradlin, 1999). This discrepancy could be related to the fact that the preexperimental tasks trained and tested nonarbitrary stimulus control while experimental tasks required arbitrary stimulus control. This history may have lead the children to seek out nonarbitrary relations among the stimuli during unreinforced test trials (i.e., when no feedback: do what you did before). Moreover, our procedures, like those in the Green (1990) study, incorporated a number of features (one-to-many training structure, abstract stimuli, match-tosample tasks with more than two comparisons, no stimulus naming by the experimenter during the first few training trials [e.g., "When face point to apple"], testing equivalence before symmetry, not mixing equivalence trials with baseline trials), each of which or in combination could have negatively affected the outcome of the equivalence test (Green, 1990; Holth \& Arntzen, 1998; Saunders et al., 1993, 1999; Sidman et al., 1986; Stromer \& Mackay, 1996). If correct, this would be an additional indication for the strength of the auditory-visual training procedure.

\section{References}

BARNES, D., BROWNE, M., SMEETS, P. M., \& ROCHE, B. (1995). A transfer of functions and a conditional transfer of functions through equivalence relations in three- to six-year-old children. The Psychological Record, 45, 405-430.

BARNES, D., MCCULLAGH, P. D., \& KEENAN, M. (1990). Equivalence class formation in non-hearing impaired children and hearing impaired children. The Analysis of Verbal Behavior, 8, 19-30. 
BOELENS, H. (2001). Emergent matching to sample and equivalence relations. European Journal of Behavior Analysis, 2, 41-42.

BOELENS, H., VAN DEN BROEK, M., \& VAN KLARENBOSCH, T. (2000). Symmetric matching in 2-year-old children. The Psychological Record, 50, 293-304.

CARPENTIER, F., SMEETS, P. M., \& BARNES-HOLMES, D. (2002). Matching functionally same relations: Implications for equivalence-equivalence as a model for analogical reasoning. The Psychological Record, 52, 351-370.

CARR, D., WILKINSON, K. M., BLACKMAN, D., \& MCILVANE, W. J. (2000). Equivalence classes in individuals with minimal verbal repertoires. Journal of the Experimental Analysis of Behavior, 74, 101-114.

DAVIDSON, H. P.(1935). A study on the confusing letters b, d, p, and q. Journal of Genetic Psychology, 47, 458-467.

DEVANY, J. M., HAYES, S. C., \& NELSON, R. O. (1986). Equivalence class formation in language-able and language-disabled children. Journal of the Experimental Analysis of Behavior, 46, 243-257.

DUGDALE, N., \& LOWE, C. F. (1990). Naming and stimulus equivalence. In D. E. Blackman \& H. Lejeune (Eds.), Behavior analysis in theory and practice (pp. 115-138). Hove (UK): Erlbaum.

EIKESETH, S., \& SMITH, N (1992). The development of functional and equivalence classes in high functioning autistic children: The role of naming. Journal of the Experimental Analysis of Behavior, 58, 123-133.

GOYOS, C. (2000). Equivalence class formation via common reinforcers among preschool children. The Psychological Record, 50, 629-654.

GREEN, G. (1990). Differences in development of visual and auditory-visual equivalence relations. American Journal on Mental Retardation, 95, 260-270.

HOLTH, P., \& ARNTZEN, E. (1998). Stimulus familiarity and the delayed emergence of stimulus equivalence or consistent nonequivalence. The Psychological Record, 48, 81-110.

HORNE, P. J., \& LOWE, C. F. (1996). On the origins of naming and other symbolic behavior. Journal of the Experimental Analysis of Behavior, 65, 185-241.

HUTTENLOCHER, J. (1967). Discrimination of figure orientation: Effects of relative position. Journal of Comparative and Physiological Psychology, 63, 359-361.

LAZAR, R. M., DAVIS-LANG, D., \& SANCHEZ, L. (1984). The formation of visual stimulus equivalences in children. Journal of the Experimental Analysis of Behavior, 41, 251-266.

LOWE, C. F., HORNE, P. J., HARRIS, F. D. A., \& RANDLE, V. R. L. (2002). Naming and the categorization in young children: Vocal tact training. Journal of the Experimental Analysis of Behavior, 78, 527-549.

MANDELL, C., \& SHEEN, V. (1994). Equivalence class formation as a function of the pronounceability of the sample stimulus. Behavioral Processes, 32, 29-46.

PILGRIM, C., \& GALIZIO, M. (1996). Stimulus equivalence: A class of correlations or a correlation of classes? In T. R. Zentall \& P. M. Smeets (Eds.), Stimulus class formation in humans and animals (pp. 173-195). Amsterdam: Elsevier.

RANDELL, T., \& REMINGTON, B. (1999). Equivalence relations between visual stimuli: The role of naming. Journal of the Experimental Analysis of Behavior, 71, 395-415.

RUDEL, R. G., \& TEUBER, H. L. (1963). Discrimination of direction of line in children. Journal of Comparative and Physiological Psychology, 56, 892-898.

SAUNDERS, K. J., SAUNDERS, R. R., WILLIAMS, D. C., \& SPRADLIN, J. E. (1993). An interaction of instructions and training design on stimulus class formation: Extending the analysis of equivalence. The Psychological Record, 43, 725-744. 
SAUNDERS, R., DRAKE, K. M., \& SPRADLIN, J. E. (1999). Equivalence class establishment, expansion, and modification in preschool children. Journal of the Experimental Analysis of Behavior, 71, 195-214.

SIDMAN, M. (1994). Equivalence relations and behavior: A research story. Boston: Authors Cooperative.

SIDMAN, M. (2000). Equivalence relations and the reinforcement contingency. Journal of the Experimental Analysis of Behavior, 74, 127-146.

SIDMAN, M., \& CRESSON, O. (1973). Reading and crossmodal transfer of stimulus equivalences in severe retardation. American Journal of Mental Deficiency, 77, 515-523.

SIDMAN, M., CRESSON, O., \& WILLSON-MORRIS, M. (1974). Acquisition of matching to sample via mediated transfer. Journal of the Experimental Analysis of Behavior, 22, 261-273.

SIDMAN, M., KIRK, B., \& WILLSON-MORRIS, M. (1985). Six-member stimulus classes generated by conditional-discrimination procedures. Journal of the Experimental Analysis of Behavior, 43, 21-42.

SIDMAN, M., \& TAILBY, W. (1982). Conditional discrimination vs. matching-tosample: An expansion of the testing paradigm. Journal of the Experimental Analysis of Behavior, 37, 5-22.

SIDMAN, M., WILLSON-MORRIS, M., \& KIRK, B. (1986). Matching-to-sample procedures and the development of equivalence relations: The role of naming. Analysis and Intervention in Developmental Disabilities, 6, 1-19.

SMEETS, P. M., \& BARNES-HOLMES, D. (2003). Children's emergent preferences for soft drinks: Stimulus equivalence and transfer. Journal of Economic Psychology, 24, 603-618.

SMEETS, P. M., LANCIONI, G. E., \& STRIEFEL, S. (1991). Establishing mirrorimage discriminations with progressively delayed extra-stimulus prompts. Journal of Experimental Child Psychology, 52, 197-220.

STODDARD, L. T., \& MCILVANE, W. J. (1986). Stimulus control research and developmentally disabled individuals. Analysis and Intervention in Developmental Disabilities, 6, 155-178.

STROMER, R., \& MACKAY, H. A. (1996). Naming and the formation of stimulus classes. In T. R. Zentall \& P. M. Smeets (Eds.), Stimulus class formation in humans and animals (pp. 221-252). Amsterdam: Elsevier.

WETHERBY, B. W., KARLAN, G. R., \& SPRADLIN, J. E. (1983). The development of derived stimulus relations through training in arbitrary-matching sequences. Journal of the Experimental Analysis of Behavior, 40, 69-78.

WOHLWILL, J. F., \& WIENER, M. (1964). Discrimination of form orientation in young children. Child Development, 35, 1113-1125.

WULFERT, E., DOUGHER, M. J., \& GREENWAY, D. E. (1991). Protocol analysis of the correspondence of verbal behavior and equivalence class formation. Journal of the Experimental Analysis of Behavior, 56, 489-504. 